\title{
Intermediate Screw pada Unstable Thoracolumbar Fracture: Case Series dan Review Article
}

\author{
Komang Agung Irianto, Dionisius Bramta Putra
}

\begin{abstract}
Abstrak
Area thorakolumbar merupakan hampir $90 \%$ dari semua spinal injuries dan $10 \%$ dari cedera tersebut merupakan burst fracture yang membutuhkan intervensi operatif. Terapi burst fracture thorakolumbar meliputi restorasi dari alignment, stabilisasi spinal, koreksi kifotik, dan dekompresi spinal kanal. Pertimbangan penggunaan intermediate screw masih menjadi topik perdebatan. Penambahan intermediate pedicle screw dipercaya dapat menambah stabilitas dan membantu koreksi kifosis pada long segment, short segment fixation. Penelitian ini merupakan systematic literature review. Pencarian literatur menggunakan mesin pencari elektronik PubMed, MEDLINE, PMC, Cochrane Library, Nature, Taylor and Francis Online dan Springerlink, dari tanggal 28 Desember 2017 sampai 20 Februari 2018. Kriteria inklusi: burst fracture dari mekanisme traumatik, fraktur tulang belakang bagian thorax atau lumbal, intermediate pedicle screw dan penelitian dari tahun 2010 sampai 2017. Ditemukan 10 artikel (15,15\%) artikel yang masuk kedalam kriteria inklusi. Terdapat tiga penelitian level 1, satu penelitian level 2, empat penelitian level 3 yang mendukung teknik SSPF+IS dengan hasil reduksi fraktur dan evaluasi radiologis yang baik, correction loss dan implant failure yang lebih rendah, mengurangi nyeri pascaoperasi. Teknik SSPF+IS merupakan teknik yang aman dan efektif memberikan hasil fiksasi yang stabil, hasil evaluasi akhir radiologis serta hasil evaluasi akhir klinis yang baik.
\end{abstract}

Kata kunci: thoracolumbar burst fracture, intermediate pedicle screw

\begin{abstract}
Almost $90 \%$ of all spinal injuries occur in the thoracolumbar area dan $10 \%$ of the injuries are burst fractures that require operative intervention. Thoracolumbar burst fracture therapy includes restoration of alignment, spine stabilization, kyphotic correction, and spinal canal decompression. The consideration of using intermediate screw is still in debate. Additional intermediate pedicle screw techniques are expected to further maintain kyphosis correction. This research was a systematic literature review. Search the literature using electronic search engines PubMed, MEDLINE, PMC, Cochrane Library, Nature, Taylor and Francis Online, and Springerlink, from December 28, 2017, to February 20, 2018. Inclusion criteria: burst fracture from traumatic mechanisms, spinal or thoracic spine fractures lumbar, intermediate pedicle screw, and research from 2010 to 2017. There were 11 articles (15.15\%) of long segment posterior fixation articles, and short posterior fixation segment combined with intermediate screw (SSPF + IS). There were three levels 1, one level 2, four level 3 research studies that support SSPF + IPS technique with fracture reduction results and improved radiological structural improvements, lower correction loss, and implant failure, reducing postoperative pain. The SSPF + IS technique was a safe and effective technique that provides stable fixation results, radiological final evaluation results and good clinical end-evaluation results.
\end{abstract}

Keywords: thoracolumbar burst fracture, intermediate pedicle screw

Affiliasi penulis: SMF Orthopaedi dan Traumatologi Fakultas

Kedokteran Universitas Airlangga-RSUD Dr. Soetomo

Korespondensi: Jl. Mayjend Prof Dr. Moestopo 6-8 Surabaya

komang168@yahoo.com Telp: (031) 5501481

\section{PENDAHULUAN}

Hampir $90 \%$ persen dari semua spinal injuries terjadi pada area thorakolumbar; $10 \%$ sampai $20 \%$ dari cedera tersebut ialah burst fracture. ${ }^{1}$ Pada kasus 
unstable burst fracture thorakolumbar dari studi metaanalisis dipaparkan teknik fiksasi short-segment memberikan hasil koreksi kifotik yang kurang baik dan loss of correction pada long-term follow up bila dibandingkan dengan fiksasi long-segment. Hanya berdasarkan evaluasi radiologis, long-segment lebih efektif untuk menjadi pilihan terapi burst fracture thorakolumbar. Short-segment punya keunggulan yaitu waktu operasi yang dibutuhkan lebih cepat. ${ }^{2}$

Burst fracture thorakolumbar disebabkan oleh kompresi vertikal ke tulang belakang dalam posisi fleksi, gaya rotational, shearing dan ekstensi, menyebabkan beberapa pola yang berbeda dalam beberapa kasus. Dari beberapa jenis burst fracture, ada jenis yang tidak stabil dengan kriteria Denis yang digunakan untuk klasifikasi fraktur thorakolumbal. Indikasi SSPSF termasuk kifosis regional >30 derajat, keruntuhan badan vertebral $>40 \%$, kompartemen kanal spinalis dengan defisit neurologis atau cedera mengenai tiga kolum. $^{3}$ Jenis klasifikasi lain menggunakan sistem klasifikasi thoracolumbar injury classification and severity score (TLICS) yang lebih merekomendasikan terapi operatif score $\geq 5$ dan terapi nonoperatif bila $\leq 3$, serta bila score 4 bisa dipertimbangkan untuk tindakan operatif. ${ }^{4}$

Permasalahan yang sering dihadapi adalah koreksi dari kifotik dan loss of correction. Saat ini dikenal adanya teknik fiksasi lain dengan menambahkan pedicle screw pada area fraktur, yang diyakini dapat mengoreksi dan mempertahankan koreksi kifotik lebih baik dari fiksasi pendek dan panjang tanpa penambahan intermediate pedicle screw. Pada studi ini akan dipaparkan teknik fiksasi dengan penambahan intermediate pedicle screw.

\section{METODE}

Penelitian systematic literature review menurut guideline Cochrane dijalankan untuk mengetahui keuntungan teknik short-segment dan intermediate screw pada cedera tulang belakang thorakolumbar. Dilakukan pencarian pada mesin pencari elektronik seperti PubMed, Medline, PMC, Cochrane Library, Nature, Taylor and Francis Online, dan Springerlink sejak tanggal 28 Desember 2017 hingga 20 Februari 2018 dengan kata kunci "intermediate pedicle screw, short segment, long segment, dan thoracolumbar fracture". Kriteria inklusi penelitian ini adalah: (1) burst fracture dari mekanisme traumatik, (2) fraktur dari tulang belakang thoraks atau lumbal dan (3) intermediate pedicle screw dan (4) penelitian dari tahun 2010 sampai 2017, Kriteria eksklusi penelitian ini adalah: (1) tambahan dengan vertebroplasty, (2) burst fracture patologis, (3) fraktur servikal, (4) idiopatic scoliosis, dan (5) penelitian biomekanis atau menggunakan kadaver. Hasil pencarian dilakukan blinding pada judul dan abstrak saja. Kriteria inklusi dan eksklusi dinilai dengan mengambil artikel penuh. Setelah itu, diambil artikel yang membahas tentang terapi operasi saja pada penelitian saat ini. Penelitian tersebut membahas tentang terapi burst fracture tulang belakang dengan short-segment fixation dan intermediate screw insertion.

Level of evidence diambil dari jurnal Clinical Orthopaedics and Related Research. Semua artikel penelitian yang didapat diklasifikasikan ke dalam tingkatan/skala tersebut. Skala level of evidence dimulai dari level 1 yang merupakan tingkatan tertinggi hingga level 5 yang merupakan tingkatan terendah. Penelitian dengan skala tingkatan 1 atau 2 level of evidence diklasifikasikan sebagai level of evidence tinggi.

Jika terjadi ambiguitas, maka peneliti meminta pendapat reviewer ketiga. Semua penelitian yang dimasukkan dalam studi ini harus dalam tingkatan level of evidence 1 atau 2. Semua data diurutkan menggunakan program Microsoft Excel (Microsoft Corp, Redmond, Washington, United State). 


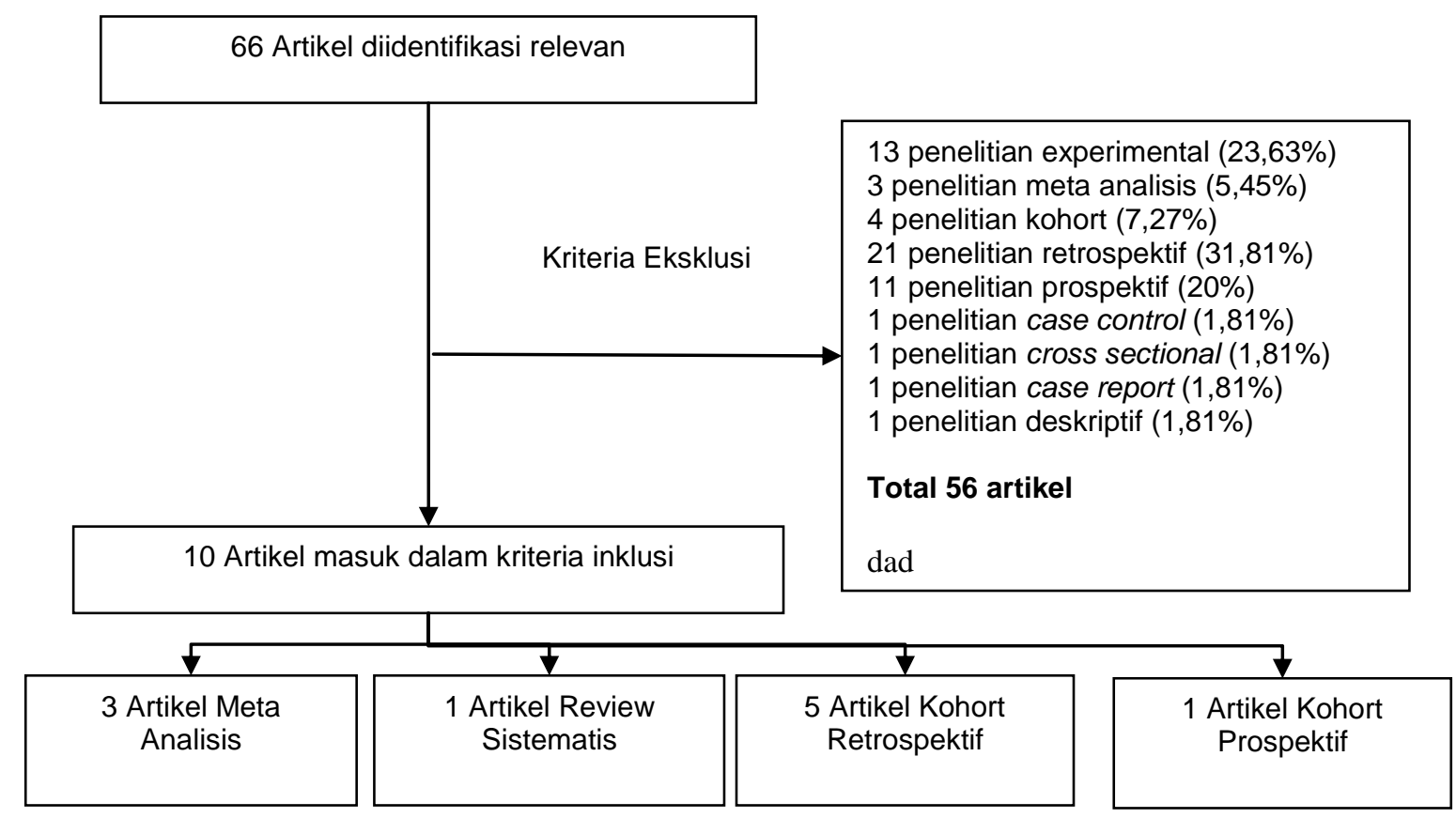

Gambar 1. Kerangka operasi penelitian

\section{HASIL}

Hasil pencarian jurnal didapatkan 66 artikel yang relevan dengan penggunaan "short-segment dan intermediate screw" pada burst fracture tulang belakang. Secara keseluruhan, ada 55 artikel yang dieksklusi karena beberapa alasan seperti yang terlihat pada Gambar 1. Terdapat 10 artikel yang masuk kedalam kriteria inklusi penelitian systematic review ini.

Dari hasil pencarian tersebut terdapat 13 penelitian eksperimental $(23,63 \%), 3$ penelitian meta analisis (5,45\%), 4 penelitian kohort (7,27\%), 21 penelitian retrospektif (31,81\%), 11 penelitian prospektif (20\%), 1 penelitian case control (1,81\%), 1 penelitian cross sectional $(1,81 \%), 1$ penelitian case report $(1,81 \%)$, dan 1 penelitian deskriptif $(1,81 \%)$ yang kami eksklusi karena tidak memberikan hasil untuk mengevaluasi terapi thoracolumbar burst fracture dengan short-segment fixation dan intermediate pedicle screw.

Penelitian yang masuk ke dalam kriteria inklusi didapatkan 1 penelitian review sistematis (10\%), 3 penelitian meta analisis (30\%), 1 penelitian kohort prospektif (10\%) dan 5 penelitian kohort retrospektif (50\%). Institusi kami menganut short segment fixation tanpa intermediate screw untuk penangana kasus unstable thoracolumbar fracture terkumpul 5 pasien yang dapat kami evaluasi loss of correction dalam follow up 1 tahun setelah operasi sebagaimana terlampir pada Tabel 1. Empat kasus unstable burst fracture yang dilakukan stabilisasi short segment tanpa intemediate screw hanya didapatkan 1 pasien yang mendapatkan hasil koreksi kifotik yang baik. Sedangkan untuk loss of correction sekitar 2 derajat dalam 1 tahun follow up pada keempat pasien.

Tabel 1. Burst fracture vertebra lumbal dengan short segment

\begin{tabular}{cclccccc}
\hline Jenis Kelamin & Umur & Diagnosis & Status Neurologi & Tindakan & Pre Op & Post Op & Loss of correction \\
\hline Laki-laki & 34 tahun & BFVL II B & Frankel D & SSw/o IS & 18 & 16 \\
\hline Laki-laki & 39 tahun & BFVL II B & Frankel D & SSw/o IS & 10 & 0 \\
\hline Laki-laki & 50 tahun & BFVL I B & Frankel C & SSw/o IS & 20 & 2 \\
\hline Laki-laki & 40 tahun & BFVL II A & Frankel D & SSw/o IS & 8 & 7 \\
\hline
\end{tabular}




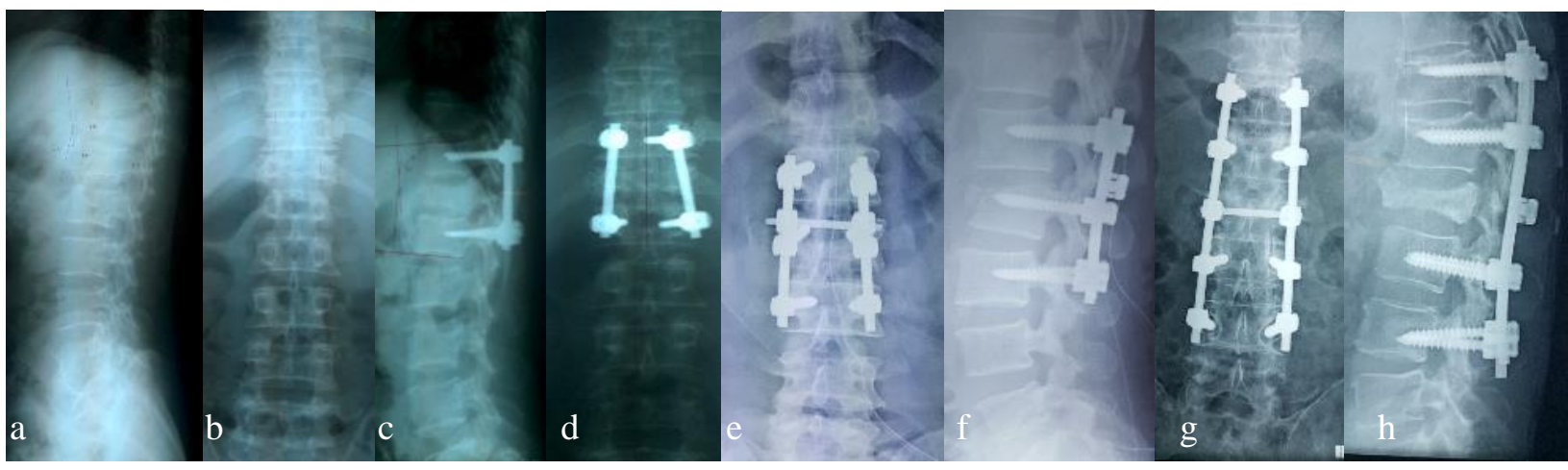

Gambar 2. (a-d) burst fracture vertebra thoracal XII dengan fiksasi short segment (pre operasi dan pascaoperasi), $(e, f)$ burst fracture vertebra lumbal dengan fiksasi short segment disertai intermediate screw (pascaoperasi), (g,h) burst fracture vertebra lumbal I dengan fiksasi long segment

\section{Studi Level 3 Evidence Based Medicine}

Mueez Waqar et al (2016) yang melakukan penelitian retrospektif melaporkan 28 pasien dengan usia rata-rata 38 tahun yang dilakukan Short-Segment Posterior Fixation (SSPF) pada 17 pasien (61\%) dan Long-Segment Posterior Fixation (LSPF) dilakukan pada 11 pasien (39\%). Didapatkan kecenderungan hasil klinis dan radiologi yang lebih baik pada LSPF, dibandingkan dengan kelompok SSPF. ${ }^{5}$

Chonglin Ye et al (2017) yang telah melakukan studi retrospektif membandingkan pasien yang menggunakan short-segment pedicle screw tanpa menggunakan intermediate screw pada fracture site (grup 1) dengan short-segment pedicle screw ditambah intermediate screw pada fracture site (grup 2) secara klinis dan radiologis selama 1 minggu, 6 bulan, dan 1 tahun pascaoperasi. Hasilnya adalah koreksi pada Cobb Angle (CA) 1 minggu pascaoperasi lebih baik pada grup 2, yang mana tinggi corpus vertebra anterior pada level fraktur (AVHF) dan rasio kompresi tidak ada perbedaan signifikan antara kedua grup. Terlebih lagi, pada grup 2 dapat menjaga stabilitas jangka panjang yaitu saat 6 bulan dan 1 tahun pascaoperasi. Reduksi pada mid-sagital spinal canal pada 1 minggu dan 1 tahun pascaoperasi lebih baik pada grup 2 yang menggunakan intermediate screw pada fracture site. ${ }^{6}$

Kose et al (2014) pada penelitian retrospektif mengevaluasi efek dari penggunaan short-segment pedicle screw instrumentation dan intermediate screw (SSPI+IS) secara radiologis berdasarkan klasifikasi load-sharing, reduksi dan remodelling pada spinal canal. Hasil rata-rata sagital indeks preoperasi terkoreksi sebesar $-1.8^{\circ}$ pascaoperasi dan tidak ada pasien yang membutuhkan revisi karena loss of correction atau kegagalan pada instrumen. Shortsegment pedicle screw instrumentation dan intermediate screw aman dan efektif untuk penanganan burst fracture thorakolumbar. Teknik ini memberikan hasil radiologis yang baik dengan angka kegagalan yang rendah tanpa melihat fraktur tersebut memiliki nilai klasifikasi yang tinggi atau rendah. ${ }^{7}$

Canbek Umut et al (2014) meneliti 25 pasien dengan unstable thoracolumbal fracture yang dilakukan operasi. Kelompok pasien dibagi menjadi yang sudah dioperasi dengan short segment intermediate screw fixation dan long-segment screw fixation. Pada penelitian ini, dilaporkan tidak ada perbedaan yang signifikan terhadap hasil evaluasi radiologis pada kedua teknik. ${ }^{8}$

Ji-Wei Tian et al (2011) meneliti secara retrospektif yaitu perbandingan fiksasi posterior shortsegment dikombinasi intermediate screws fraktur thorakolumbar dengan conventional intersegmental fixation yang dinilai dengan vertebral body height dan kyphotic angle preoperasi dan pascaoperasi. Hasilnya terdapat perbedaan yang signifikan pada rata-rata perubahan pada segmental kyphotic angle pada shortsegment yang dikombinasikan dengan intermediate screws lebih besar dibandingkan dengan cara konvensional. Hasil ini mengindikasikan kombinasi short-segment dengan intermediate screw lebih efektif dalam mengembalikan tinggi vertebral body yang dihubungkan dengan kyphotic angle dan mobilisasi lebih awal. ${ }^{9}$ 


\section{Studi Level 2 Evidence Based Medicine}

Anghel $S$ et al (2013) meneliti dengan systematic review sejak tahun 2000 sampai 2012 mengenai perbandingan penggunaan short-segment pedicle screw dibandingkan dengan short-segment pedicle screw dengan penambahan intermediate screw dengan tujuan potensi untuk mencegah loss of correction. Hasilnya adalah penambahan satu atau dua screw pada fraktur level (intermediate screw) tidak memberikan dampak yang signifikan dibandingkan dengan cara tradisional (short-segement screw). ${ }^{10}$

Gajjar et al (2016) meneliti 32 pasien yang mengalami cedera thorakolumbar yang akan dioperasi dengan teknik stabilisasi short-segment posterior dengan transpedicular screw yang akan dievaluasi preoperasi dan pascaoperasi. Hasil penelitian ini terdapat perbedaan yang signifikan antara sudut regional dan ketinggian tulang belakang pada evaluasi preoperasi dan pascaoperasi. Teknik short-segment posterior merupakan implan yang stabil untuk mempertahankan koreksi deformitas dan reduksi fraktur sejalan dengan keuntungan menyisakan gerakan segmen. ${ }^{11}$

\section{Studi Level 1 Evidence Based Medicine}

Min-ji Tong et al (2017) secara meta-analisis dari penelitian randomized controlled trial yang membandingkan secara klinis dan radiologis hasil dan komplikasi posterior pedicle screw yang dikombinasikan dengan intermediate screw dengan intersegmental pedicle screw konvensional. Hasilnya adalah kombinasi dengan menggunakan intermediate screw memiliki hasil secara radiologis yang lebih baik secara signifikan dibandingkan dengan cara konvensional. $^{12}$

Kunpeng Li et al (2016) secara meta-analisis dengan teknik studi kohort membandingkan pedicle screw yang dikombinasikan dengan intermediate screw dengan teknik konvensional pada fraktur thorakolumbar. Hasil yang diukur adalah Visual Analoque Score (VAS), Cobb Angle dan komplikasi. Hasilnya adalah teknik kombinasi menghasilkan reduksi fraktur yang lebih baik dibandingkan teknik konventional, lebih sedikit correction loss, implant failure yang lebih sedikit. ${ }^{13}$
Aly et al (2017) melakukan penelitian metaanalisis terhadap studi-studi randomized, quasirandomized, controlled clinical trial. Penelitian ini membandingkan antara teknik short-segment dengan long-segment pedicle screw fixation pada fraktur burst thorakolumbar. Terdapat 9 penelitian clinical trial yang masuk ke dalam kriteria inklusi. Hasil dari metaanalisis ini adalah kedua teknik tersebut mempunyai fiksasi yang stabil dan rasa nyeri pascaoperasi berkurang secara signifikan dari kedua grup. Kejadian dari loss of correction juga rendah di kedua grup. Secara statistik menunjukan tidak ada perbedaan pada kedua teknik ini dan mempunyai kualitas hasil evaluasi radiologis dan klinis yang sama baiknya. ${ }^{14}$

\section{PEMBAHASAN}

Tujuan dari terapi pada pasien traumatic thoracolumbar burst fracture adalah mobilisasi awal pasien dan tulang belakang yang tidak nyeri, seimbang dan stabil. Mobilitas tulang belakang yang maksimal dan fungsi neurologis yang optimal. Pada penelitian terbaru yang membahas tentang teknik operasi ini ditemukan 10 artikel (15,15\%) pada Medline, PMC, Cochrane Library, Nature, Taylor and Francis Online, dan Springerlink yang membahas teknik long segment fixation, short segment posterior fixation, dan short segment yang dikombinasikan dengan intermediate pedicle screw.

Pilihan short segment fixation didukung oleh Gajjar et al (2016) evidence based level II melaporkan teknik short-segment posterior merupakan implan yang stabil untuk mempertahankan koreksi deformitas dan reduksi fraktur sejalan dengan keuntungan menyisakan gerakan segmen. ${ }^{11}$

Pada penelitian dengan evidence based level I oleh Aly et al (2017) melaporkan bahwa penggunaan teknik short segment dan long segment tidak didapatkan perbedaan baik dari stabilitas, hasil koreksi kifotik, maupun kejadian loss of correction dari radiologis, dan klinis setelah operasi yang sama baiknya. $^{14}$

Teknik yang saat ini banyak diminati yaitu short segment posterior yang dikombinasikan dengan intermediate screw memiliki hasil reduksi fraktur yang lebih baik sehingga hasil akhir radiologis lebih baik 
dibandingkan dengan cara konvensional atau tanpa kombinasi intermediate screw. Kejadian dari correction loss dan implan failure dilaporkan lebih sedikit. Subjek Min Ji Tong et al dan Kunpeng et al mendukung hasil tersebut pada penelitian mereka yang termasuk dalam klasifikasi Level of Evidence pada level 1. Penelitian meta-analisis tersebut melibatkan enam penelitian RCT dan sepuluh penelitian RCT dengan populasi yang representatif dan jumlah yang cukup menggunakan randomisasi dan menggunakan sistem review yang sesuai dengan sistem Cochraine. ${ }^{12,13}$

Hasil radiologis yang baik dan angka kegagalan yang rendah juga dilaporkan pada penelitian Level of Evidence pada level 3 oleh Kose et al. Data yang relevan dan akurat yang diambil pada penelitian ini memperkuat pertimbangan bahwa teknik short segment posterior fixation yang dikombinasikan dengan intermediate screw memiliki hasil radiologis yang baik dengan angka kegagalan yang rendah tanpa melihat fraktur tersebut memiliki nilai klasifikasi yang tinggi atau rendah. ${ }^{7}$

Canbek et al yang masuk dalam Level of Evidence pada level 3. Penelitian tersebut memberikan hasil bahwa tidak didapatkan perbedaan yang signifikan antara short segment intermediate screw fixation dan long-segment screw fixation pada hasil evaluasi radiologis. Walaupun jumlah sampel yang tidak representatif menjadi kemungkinan tidak ditemukannya perbedaan yang signifikan pada kedua grup perbandingan. ${ }^{8}$

Chonglin Ye et al (2017) yang termasuk dalam penelitian level 3 evidence based juga melaporkan grup yang dioperasi dengan teknik short segment dikombinasi dengan intermediate screw menghasilkan Cobb Angle yang terkoreksi dan terjaga pada level fraktur pada 1 minggu, 6 bulan, 1 tahun setelah operasi. Karakteristik pada kedua grup belum dapat disimpulkan merepresentasikan sampel penelitian, akan tetapi penelitian ini memiliki data yang valid untuk digunakan. ${ }^{6}$

Ji-Wei Tian et al (2011) yang termasuk dalam penelitian evidence based level 3 melaporkan shortsegment dengan intermediate screw lebih efektif dalam mengembalikan tinggi vertebral body dan koreksi kifotik jika dibandingkan dengan shortsegment tanpa intermediate screw. ${ }^{9}$
Hasil yang berbeda ditemukan pada penelitian Anghel et al (Level of Evidence: Level 2) yang melaporkan bahwa tidak ada perbedaan yang signifikan pada hasil akhir dari evaluasi radiologis, evaluasi klinis dan kemampuan fiksasi untuk mencegah terjadinya loss of correction pada teknik short segment without intermediate screw dan short segment with intermediate screw. Pada penelitian yang dilaporkan Anghel et al merupakan sistematik review yang mengikutsertakan 14 penelitian, akan tetapi tidak dijelaskan jenis penelitian dan Level of Evidence dari penelitian tersebut sehingga kurang representatif. $^{10}$

Hasil yang bertentangan terdapat pada Mueez Waqar et al (2016) pada penelitian Level of Evidence level 3 melaporkan kecenderungan hasil klinis dan radiologis yang lebih baik pada long segment posterior fixation (LSPF), dibandingkan dengan kelompok short segment posterior fixation (SSPF). ${ }^{5}$

Peran intermediate screw yang memberikan fiksasi yang lebih stabil dengan hasil radiologis dan klinis yang baik ditunjukkan 3 penelitian Level of Evidence level 1, 1 penelitian Level of Evidence level 2 dan 4 penelitian Level of Evidence level 3. Terdapat satu penelitian dengan evidence based medicine level 2 mengungkapkan peranan dari intermediate screw memberikan ruang gerak sendi yang lebih banyak. Dari review sistematis yang sangat kuat, penambahan intermediate screw dapat memberikan kekuatan fiksasi dan meningkatkan stabilitas fiksasi sehingga nyeri yang dirasakan oleh pasien yang diterapi dengan penambahan teknik ini berkurang. Dengan berkurangnya nyeri, hasil evaluasi klinis menunjukkan fungsional yang lebih baik. Intermediate screw juga memberikan hasil evaluasi radiologis yang lebih baik. Penelitian ini dilakukan sesuai dengan Cochraine Collaboration Hanbooks on Systematic Review. Karena keterbatasan dari penelitian yang ditemukan pada PubMed, penelitian ini memerlukan penelitian investigasi lebih lanjut berupa studi RCT, dengan evaluasi yang lebih lama.

Diperlukan penelitian RCT dan kohort prospektif lebih lanjut untuk memberikan gambaran hasil yang lebih spesifik pada peranan intermediate pedicle screw fixation short segment posterior fixation pada pasien thoracolumbar burst fracture. 


\section{SIMPULAN}

Terapi short segment posterior fixation lebih baik dibandingkan long segment posterior fixation. Penambahan intermediate screw pada short segment posterior fixation memberikan stabilitas tambahan pada area fraktur sehingga mengurangi nyeri setelah operasi, membantu pada saat reduksi sehingga koreksi kifotik lebih baik, dapat mempertahakan koreksi kifotik, dan menambahkan stabilitas ekstra sehingga memperkecil resiko loss of correction.

\section{UCAPAN TERIMA KASIH}

Terima kasih kepada staf Pengajar SMF Orthopaedi dan Traumatologi Fakultas Kedokteran Universitas Airlangga-RSUD Dr. Soetomo.

\section{DAFTAR PUSTAKA}

1. Holdsworth F. Review article fractures, dislocations, and fracture-dislocations of the spine. The Journal of Bone \& Joint Surgery. 1970;52(8):1534-51.

2. Assunção Filho C, Simões F, Prado G. Thoracolumbar burst fractures, short $X$ long fixation: a meta-analysis. Coluna/Columna. 2016; 15(1):78-84.

3. Denis F. The three column spine and its significance in the classification of acute thoracolumbar spinal injuries. Spine. 1983; 8 (8): 817-31.

4. Lee J, Vaccaro A, Lim M, Öner F, John Hulbert R, Hedlund $R$, et al. Thoracolumbar injury classification and severity score: a new paradigm for the treatment of thoracolumbar spine trauma. Journal of Orthopaedic Science. 2005;10(6):671-5.

5. Waqar M, Van-Popta D, Barone D, Bhojak M, Pillay R, Sarsam Z. Short versus long-segment posterior fixation in the treatment of thoracolumbar junction fractures: a comparison of outcomes. British Journal of Neurosurgery. 2016;31(1):54-7.

6. Ye C, Luo Z, Yu X, Liu H, Zhang B, Dai M. Comparing the efficacy of short-segment pedicle screw instrumentation with and without intermediate screws for treating unstable thoracolumbar fractures. Medicine. 2017; 96 (34): e7893.

7. Kose K, Inanmaz M, Isik C, Basar H, Caliskan I, Bal E. Short segment pedicle screw instrumentation with an index level screw and cantilevered hyperlordotic reduction in the treatment of type-A fractures of the thoracolumbar spine. The Bone \& Joint Journal. 2014;96-B(4): 541-7.

8. Canbek U, Karapinar L, I merci A, Akgun U, Kumbaraci $M$, Incesu $M$. Posterior fixation of thoracolumbar burst fractures: Is it possible to protect one segment in the lumbar region? European Journal of Orthopaedic Surgery \& Traumatology. 2013;24(4):459-65.

9. Tian J, Wang L, Xia T, Liu C, Zhao Q, Dong S. Posterior Short-segmental Fixation Combined with Intermediate Screws vs Conventional Intersegmental Fixation for Monosegmental Thoracolumbar Fractures. Orthopedics. 2011 Aug 8;34(8):e389-96.

10. Anghel S, Márton D. Short segment fixation versus short segment fixation with pedicle screws at the fracture level for thoracolumbar burst fracture. Acta Medica Marisiensis. 2014;60(2).49-52.

11. Gajjar S. Outcomes of short segment posterior instrumentation in unstable thoracolumbar fractures. J Clin Diagn Res. 2016;10(11):RC04RC08.

12. Tong MJ, Tang Q, Wang C, Xiang G, Chen Q, Xu $\mathrm{H}$, et al. Efficacy of using intermediate screws in short-segment fixation for thoracolumbar fractures: a meta-analysis of randomized controlled trials. World Neurosurgery. 2018;110:e271-e80.

13. Li K, Zhang W, Liu D, Xu H, Geng W, Luo D, et al. Pedicle screw fixation combined with intermediate screw at the fracture level for treatment of thoracolumbar fractures. Medicine. 2016; 95 (33): e4574.

14. Aly T. Short segment versus long segment pedicle screws fixation in management of thoracolumbar burst fractures: meta-analysis. Asian Spine Journal. 2017;11(1):150. 